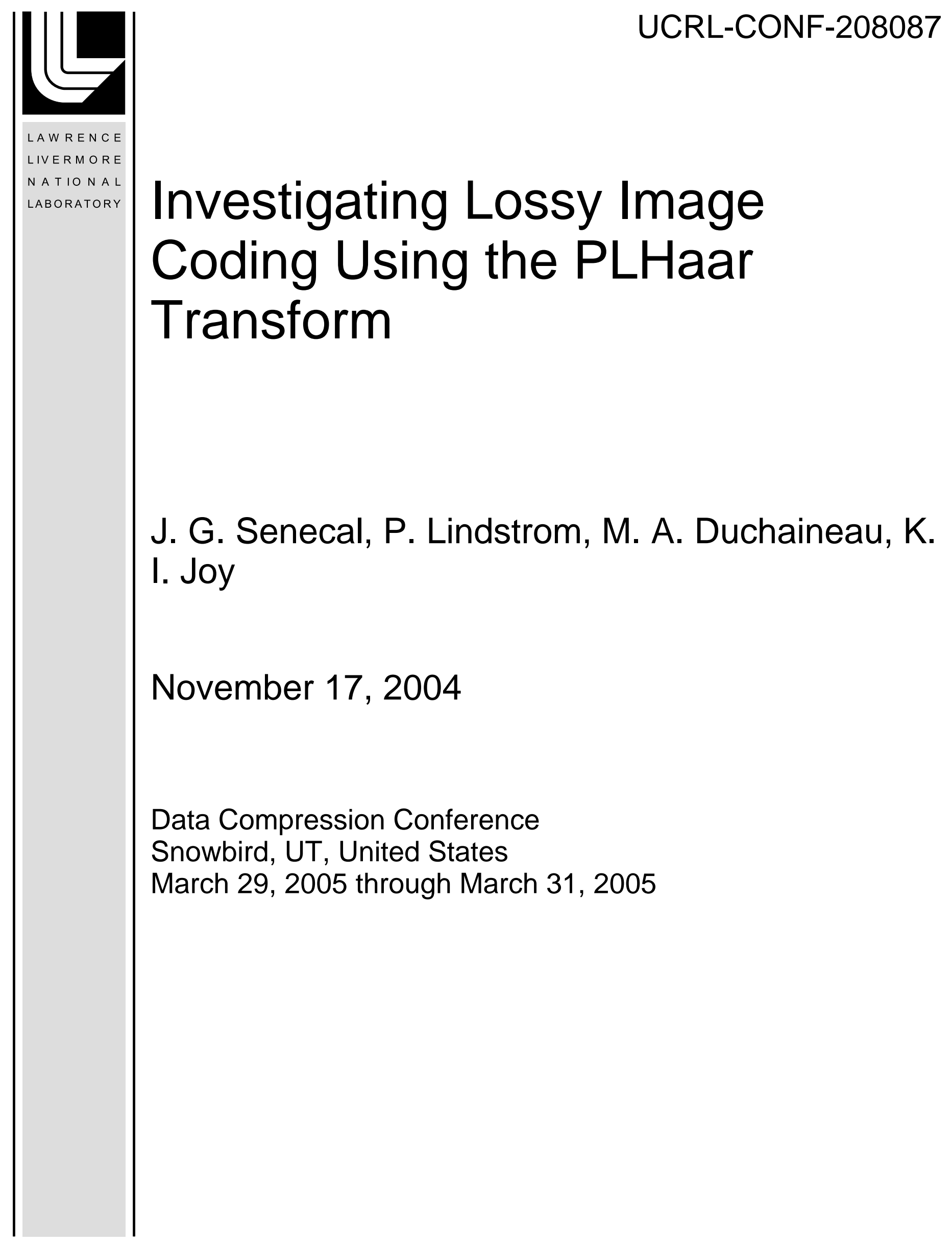


This document was prepared as an account of work sponsored by an agency of the United States Government. Neither the United States Government nor the University of California nor any of their employees, makes any warranty, express or implied, or assumes any legal liability or responsibility for the accuracy, completeness, or usefulness of any information, apparatus, product, or process disclosed, or represents that its use would not infringe privately owned rights. Reference herein to any specific commercial product, process, or service by trade name, trademark, manufacturer, or otherwise, does not necessarily constitute or imply its endorsement, recommendation, or favoring by the United States Government or the University of California. The views and opinions of authors expressed herein do not necessarily state or reflect those of the United States Government or the University of California, and shall not be used for advertising or product endorsement purposes. 


\title{
Investigating Lossy Image Coding Using the PLHaar Transform
}

\author{
Joshua G. Senecal $^{* \ddagger}$ Peter Lindstrom ${ }^{\dagger} \quad$ Mark A. Duchaineau $^{\dagger} \quad$ Kenneth I. Joy ${ }^{\ddagger}$ \\ ${ }^{*} \mathrm{ISCR},{ }^{\dagger} \mathrm{CASC}$ \\ ${ }^{\ddagger} \mathrm{IDAV}$ \\ Lawrence Livermore National Laboratory University of California, Davis
}

We developed the Piecewise-Linear Haar (PLHaar) transform [2], an integer wavelet-like transform. PLHaar does not have dynamic range expansion, i.e. it is an $n$-bit to $n$-bit transform. To our knowledge PLHaar is the only reversible $n$-bit to $n$-bit transform that is suitable for lossy and lossless coding.

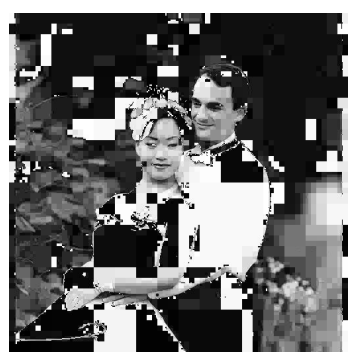

$C F H: 8.04$

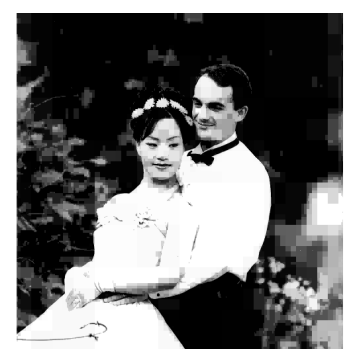

PLHaar : 20.27

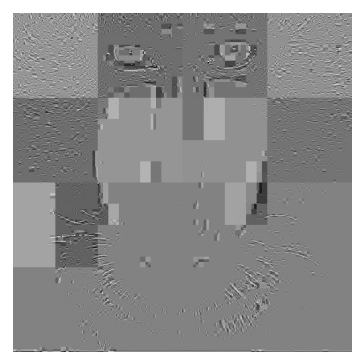

$C F H: 16.93$

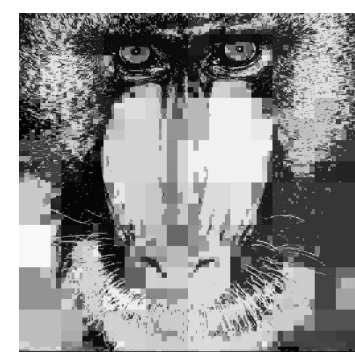

PLHaar : 13.85

Figure 1: Comparison of CFH and PLHaar for two images. PSNR is given under each image. All images are reconstructed from coefficients having an approximate zero-order entropy of 0.5 bits per pixel.

We are investigating PLHaar's use in lossy image coding. Preliminary results from thresholding transform coefficients show that PLHaar does not produce objectionable artifacts like prior $n$-bit to $n$-bit transforms, such as the transform of Chao et al. (CFH) [1]. Also, at lower bitrates PLHaar images have increased contrast. For a given set of CFH and PLHaar coefficients with equal entropy, the PLHaar reconstruction is more appealing, although the PSNR may be lower.

\section{References}

[1] Honyang Chao, Paul Fisher, and Zeyi Hua. An approach to integer wavelet transformations for lossless image compression. In Chen, Li, Micchelli, and Xu, editors, Advances in Computational Mathematics, volume 202 of Lecture Notes In Pure and Applied Mathematics, chapter 2, pages 13-38. Marcel Dekker, Inc., 1999.

[2] Joshua G. Senecal, Peter Lindstrom, Mark A. Duchaineau, and Kenneth I. Joy. An improved n-bit to n-bit reversible haar-like transform. In Proceedings of the 12th Pacific Conference on Computer Graphics and Applications, pages 371-380. IEEE Computer Society, October 2004.

${ }^{*}$ L-419, PO Box 808, Livermore, CA 94551, Tel: 925-422-3764, senecal1@llnl.gov 